\title{
Characterization 410 Stainless Steel by Vacuum Tempering Process
}

\author{
Dr.Ram.Subbiah ${ }^{1}$, B.Uday Babu ${ }^{2}$, C.Dinesh Reddy ${ }^{3}$, D.Praharsha ${ }^{4}$, E.Ajay Babu ${ }^{5}$, \\ Dr.R.Rajavel ${ }^{6}$
}

\author{
${ }^{1}$ Associate Professor, Mechanical Engineering Department, GRIET, Hyderabad, India \\ 2, 3,4,5 B.Tech Mechanical Engineering Department, GRIET, Hyderabad, India \\ ${ }^{6}$ Professor \& HOD, Mechanical Engineering Department, AMET University, Chennai, India
}

\begin{abstract}
It has been reported that low-temperature vacuum tempering of 410 stainless steel hard layer improving wear resistance and hardness. Grade 410 stainless steel being a hardened material were modified by low temperature tempering process. By the process of tempering, brittleness on the stainless steel material will be reduced and ductility will be promoted. The microstructure, surface hardness and erosion-corrosion resistance were systematically evaluated. Vacuum tempering is done at low temperature of $430^{\circ} \mathrm{C}$ can form a hardened layer, and with the treated time prolong, the thickness of the layer increased. The stainless specimens were vacuum tempered for 30 minutes, 60 minutes and 120 minutes. Wear tests were conducted with the help of pin on disc apparatus. The output results were determined with various metallographic tests like scanning electron microscope and optical microscope results.
\end{abstract}

Keywords- vacuum tempering, brittleness, wear resistance, metallographic results.

\section{INTRODUCTION}

Stainless steel with excellent corrosion resistance was widely used for surgical and medical instruments. But due to its low hardness and poor wear resistance, life of the material is limited. Hence it limits their applications in manufacture of mechanical parts for engineering equipment and machines, where both corrosion resistance and wear resistance are required. Many attempts have been made to develop surface engineering techniques to enhance the wear resistance of austenitic SS without deteriorating the corrosion resistance. These techniques include low temperature vacuum tempering, low temperature gas hardening and low temperature hardening. Low temperature vacuum tempering is a commercial process and one of the easiest methods in improving the wear resistance of 410 series of stainless steel material.
In the present study a thick case hardened layer is obtained with high hardness is obtained using vacuum tempering process at $450^{\circ} \mathrm{C}$. The untreated sample has the worn morphology of adhesive wear while the treated sample has the worn morphology of abrasive wear. It has been established that the types of chemical reactions occurred on the surface as well as the diffusion of the ferrite and cementite layer into the material during the heat treatment process determine the case depth.

\section{MATERIALS USED}

The materials used in the present work were carried out with 410 stainless steel. The specimens were prepared in following forms. (i) Polished cylindrical disc specimen measuring $50 \mathrm{~mm}$ diameter and $10 \mathrm{~mm}$ height were used. (ii) Pin specimen with diameter $8 \mathrm{~mm}$ and height $30 \mathrm{~mm}$ were used with taper edged surface.

\section{TREATMENTS}

Prior to all treatments, the specimens were cleaned ultrasonically, rinsed and dried, with care taken to avoid finger contact. Before vacuum tempering process, the specimens were sand blasted, pickled in $15 \%$ sulphuric acid for 20 minutes. The samples were degreased using acetone and preheated in an air circulated furnace for 15 minutes. The specimens were tempered and reheated at low temperature in order to improve the property of ductility.

\section{WEAR MEASUREMENTS}

Wear tests were carried out on a pin on disc machine. A stationery pin was mounted horizontally against a vertically rotating disc. The disc is rotated at a constant speed of 1000 rpm at a constant load of $2 \mathrm{Kg}$, which was applied continuously for a fixed period of 5 minutes under dry conditions. Wear test was conducted and the samples were replaced in the following order Untreated and treated 
samples respectively. The weights of the specimens were measured using a standard caliberometer. The difference between the specimen before and after testing gives the wear loss.

\section{RESULTS AND DISCUSSIONS}

The results of vacuum tempering specimens were compared with the untreated 410 specimen and it was found that, in specimen, the mixture of cementite were precipitated on the surface, to improve the hardness of material. The wear rate of untreated specimen is specified to be lower that of vacuum tempered material. Hence good surface hardness is obtained.

\section{Optical Microscope Results}

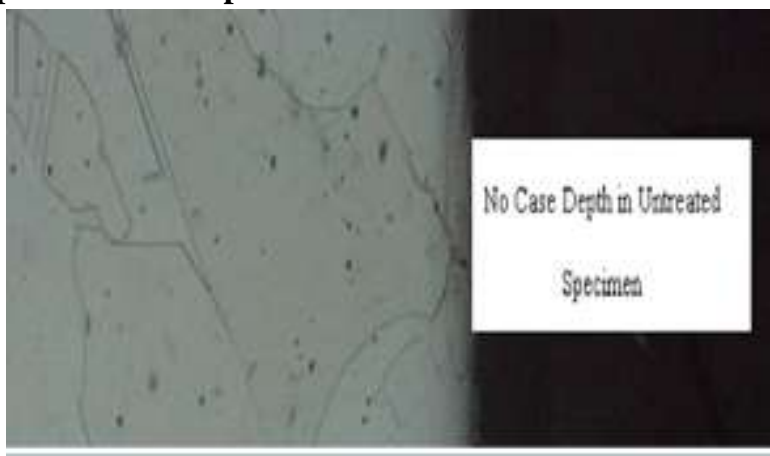

Fig. 1: Untreated Specimen

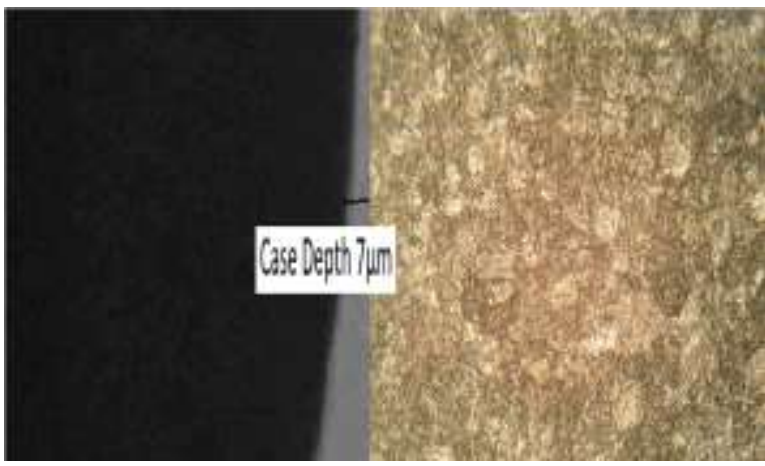

Fig.2: Vacuum Tempering for 30 minutes 7 microns

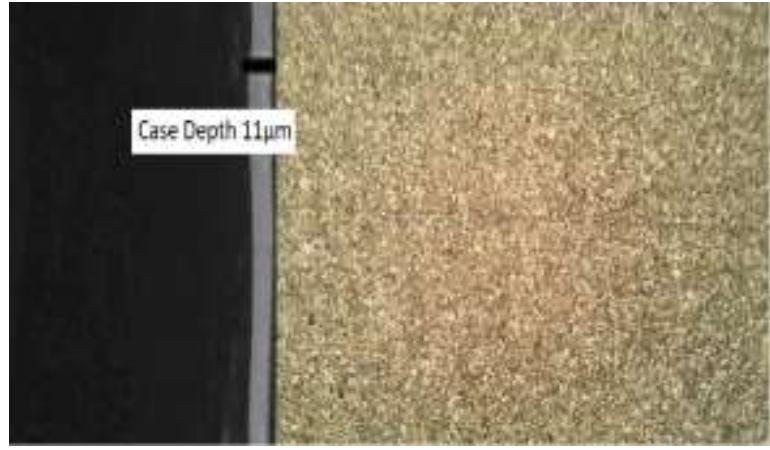

Fig.3: Vacuum Tempering for 60 minutes 11 microns

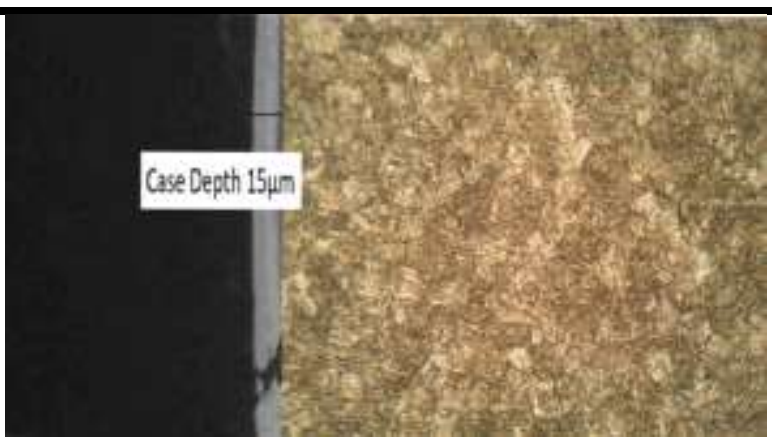

Fig.4: Vacuum tempering for 120 minutes 15 microns

Scanning Electron Microscope Results

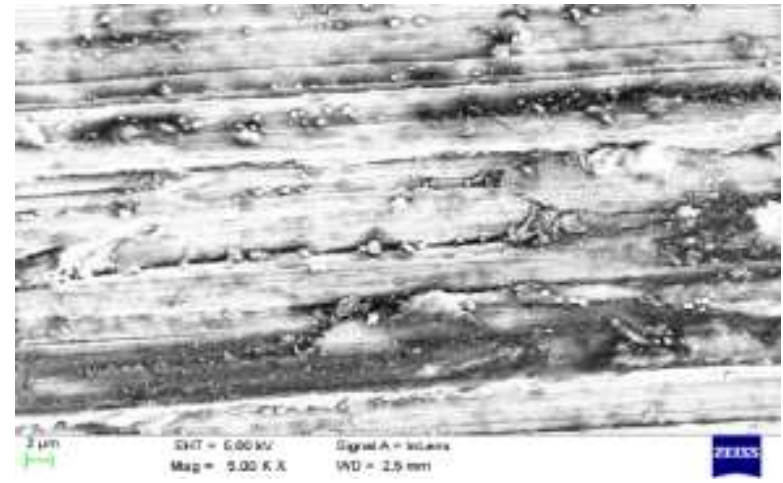

Fig.5: Untreated Specimen - SEM Image

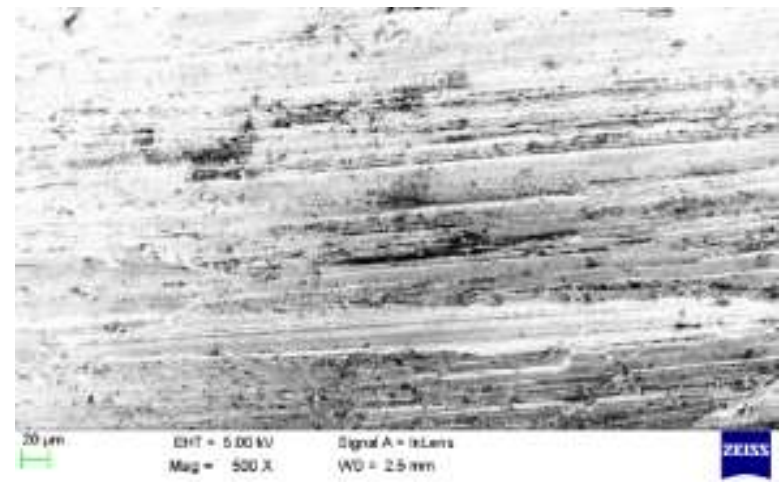

Fig.6: SEM Image for vacuum Tempering for 30 minutes

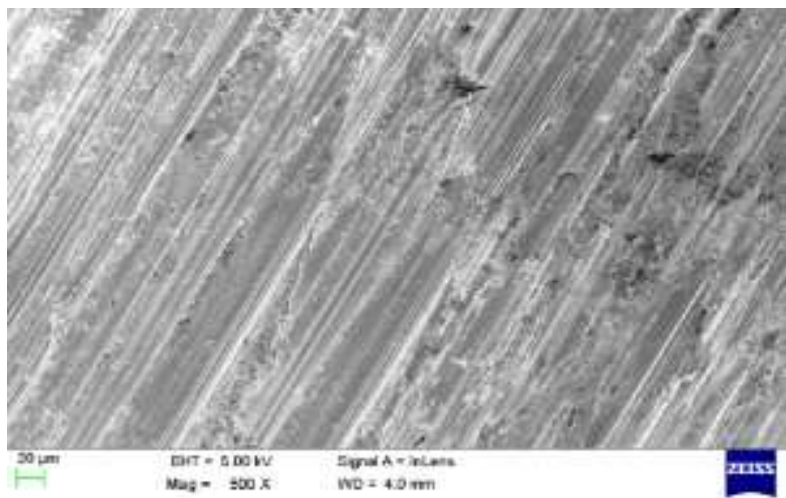

Fig.7: SEM Image for vacuum Tempering for 60 minutes 


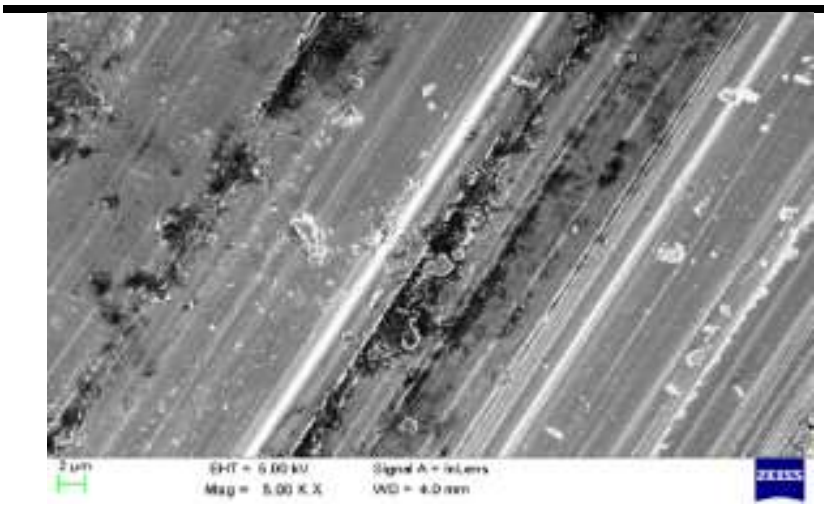

Fig.8: SEM Image for vacuum Tempering for 120 minutes

As the time of heat treatment process increases, case depth also increases. From the optical microscope results, THE hardened layer was found out in the vacuum tempered specimen arising from 7 microns to 15 microns. The peel of material was found to be very high in untreated sample. As the time of heat treatment increases, the peel of material gets decreases which were analyzed from pin on disc wear testing analysis.

\section{REFERENCES}

[1] Harshad Bhadeshia, Robert Honeycombe, "Tempering of Martensite steels" Microstructure and Properties (Fourth edition), 2017, Pages 237-270

[2] Xinfeng Li, Jin Zhang, Sicong Shen, Yanfei Wang, Xiaolong Song, "Effect of tempering temperature and inclusions on hydrogen-assisted fracture behaviors of a low alloy steel" Materials Science and Engineering: A, Volume 682, 13 January 2017, Pages 359-369

[3] Guanghua Yan, Lizhan Han, Chuanwei Li, Xiaomeng Luo, Jianfeng $\mathrm{Gu}$, "Characteristic of retained austenite decomposition during tempering and its effect on impact toughness in SA508 Gr.3 steel" Journal of Nuclear Materials, Volume 483, January 2017, Pages $167-175$

[4] C.W. Li, L.Z. Han, X.M. Luo, Q.D. Liu, J.F. Gu, "Effect of tempering temperature on the microstructure and mechanical properties of a reactor pressure vessel steel" Journal of Nuclear Materials, Volume 477, 15 August 2016, Pages 246-256

[5] Bao-Sheng Xie, Qing-Wu Cai, Yang Yun, Gao-Sheng Li, Zhen Ning, "Development of high strength ultraheavy plate processed with gradient temperature rolling, intercritical quenching and tempering" Materials Science and Engineering: A, Volume 680, 5 January 2017, Pages 454-468
[6] Hong-xiao CHI, Dang-shen MA, Hui-xia XU, Wanglong ZHU, Jian-qing JIANG, "Phase Transformation of a Cold Work Tool Steel during Tempering”, Journal of Iron and Steel Research, International, Volume 23, Issue 5, May 2016, Pages 484-488

[7] Lakshmiprasad Maddi, A.R. Ballal, D.R. Peshwe, R.K. Paretkar, K. Laha, M.D. Mathew, "Effect of tempering temperature on the stress rupture properties of Grade 92 steel" Materials Science and Engineering: A, Volume 639, 15 July 2015, Pages 431-438

[8] D.C. Saha, E. Biro, A.P. Gerlich, Y. Zhou, "Effects of tempering mode on the structural changes of martensite" Materials Science and Engineering: A, Volume 673, 15 September 2016, Pages 467-475

[9] H. Li, S. Gao, Y. Tian, D. Terada, A. Shibata, N. Tsuji, "Influence of Tempering on Mechanical Properties of Ferrite and Martensite Dual Phase Steel" Materials Today: Proceedings, Volume 2, Supplement 3, 2015, Pages S667-S671

[10] H.S.Hasan, M.J. Peet, M-N. Avettand-Fènoël, H.K.D.H. Bhadeshia, "Effect of tempering upon the tensile properties of a nanostructured bainitic steel" Materials Science and Engineering: A, Volume 615, 6 October 2014, Pages 340-347 